\title{
INTERNATIONAL COMPARISONS IN THE IMPROVEMENT OF EDUCATION
}

\begin{abstract}
Imperfections-such as inequality and inefficiency oflearning-are perennial problems for education despite a diversity of foundations on which national systems are established, which range from the idealistic vision of fostering a utopian society to the utilitarian objective of producing skilled workers capable of engendering economic growth. Despite sharing many common conditions and fundamental values, educators rarely learn valuable lessons from the successes and failures of highly relevant initiatives in distant nations. This problem may be attributed to several factors, not the least of which includes the entrenchment of local traditions and ethnocentric assumptions, but surely the quality and relevance of international-comparative research - and the way its results are disseminated - are issues that must also be taken into careful consideration. What are the unique lessons to be learned from international comparisons, and what are the prospective risks for how such comparisons may be misinterpreted and misused in educational settings? How can international comparative research be made more relevant, with tangible applications that may be recognized and effectively used by school teachers? How can international comparative education meaningfully examine subjects beyond the reach of standardized testing, in such domains as the fostering of creativity, talent, and ethical sensibilities, for example? These themes will be presented through discussion of both research findings and anecdotes from the personal experience of working for universities on four continents. Specific topics will include the challenges of accounting for conceptual equivalency and representing cultural differences, sampling and generalizability, reconciling the diverging aims of economic, anthropological, sociological, and psychological research, as well as grappling with the ambivalent discourse of globalization, multiculturalism, post-colonialism, and other social movements.
\end{abstract}

Keywords: international education, comparative education, educational policy, evaluation, educational philosophy, research methodologies, globalization, multiculturalism, postcolonialism, indigenous epistemologies, democracy, social justice

\section{INTRODUCTION}

\section{Fostering Love of Learning and Global Awareness}

If one takes a brief moment to consider the bigger picture of what really matters in educational policy, one unassailable truth seems tacitly understood: essentially, we want to leave a better world to the next generation. Despite an array of diverse opinions, philosophical orientations, and political arguments, the vast majority of educators and parents can at least agree on this essential point. Moreover, it is undeniably reasonable to suggest that if through education we can manage to instill in students a genuine love of learning, they will stand a better chance of enjoying fulfilling and productive lives, since through lifelong learning they may continue to reflect, devise and implement desirable developments across the lifespan that improve conditions for themselves, their families, and the world around them. Through promotion of a 
more widespread love of learning we may expect to see greater evidence of positive values that lead to socially healthy communities: human rights, civil liberties, and robust intellectual and artistic production. What might teachers and educational policy makers do differently to more effectively nurture students toward developing such habits of curiosity as well as critical and reflective thinking that engender responsible and creative action, enabling them to increasingly lead fulfilling, healthy and productive lives?

Here is where the development of stronger international awareness becomes an important objective for the field of teacher education, despite the fact that in most educational systems global understanding is typically neglected in favor of numeracy, literacy, technical skills, and other desired outcomes. Global awareness enables a broad understanding of the very nature of human life, leading to greater opportunities for success in most any human endeavor or occupation, from sciences to arts, governance and commerce. Nevertheless, it is often neglected. By choosing from an early age to regard distant nations as irrelevant, many students habitually accustom themselves to the lifelong blinders of a narrow world confined by conventional thought and behavior. As seen in many contemporary societies, this well-trodden path tends to yield a lifestyle of capitalistic hedonism that elevates personal comfort as a supreme virtue, promoting indifference and assumed superiority over "others". Such a direction clearly confounds efforts to leave a better world for the next generation, and if not effectively curbed in teacher education it inevitably places the aforementioned basic foundations of education in peril. Robust teacher education, therefore, requires international awareness of the kind that can only be generated through production and dissemination of specialized research that serves as a foundation for curricular and policy-related decisions.

In this brief article, based on a keynote speech offered for the Sixth International Scientific Conference: Theory for Practice in the Education of Contemporary Society (March 2931, 2012, Riga Teacher Training and Education Management Academy), some succinct thoughts will be offered regarding how international-comparative research enriches the field of teacher education, with particular attention to the following themes.

\section{THE AIM OF THE STUDY}

(1) What are the unique lessons to be learned from international comparisons, and what are the prospective risks for how such comparisons may be misinterpreted and misused in educational settings?; and (2) How can international comparative research be made more relevant, with tangible applications that may be recognized and effectively used by school teachers?

\section{MATERIALS AND METHODS}

The article will begin with identification of some fundamental challenges for research methodologies used in comparative studies, followed by an overview of theoretical paradigms (and associated ideologies) commonly encountered in international-comparative education research. Next will be a description of a major challenge in this field: how international comparison bolsters an evaluation mandate that promotes a superficial global awareness while stifling originality by displacing the core objectives of education. Author will argue that this problem opens the need for more comparative research on underexplored themes, and proceed to identify relevant organizations, institutions, and funding bodies that may be approached to support such projects. The article concludes with succinct discussion of some educational policy recommendations for small nations as well as practical suggestions for globally conscious teaching. It is author's hope that this overview of basic issues and current topics may inspire those who are relatively unfamiliar with international comparative studies to consider carefully examining this promising field of research. 


\section{Methodological Issues and Theoretical Paradigms}

Imperfections - such as inequality and inefficiency of learning - are perennial problems for education despite a diversity of foundations on which national systems are established, which range from the idealistic vision of fostering a utopian society to the utilitarian objective of producing skilled workers capable of engendering economic growth. Despite sharing many common conditions and fundamental values, educators rarely learn valuable lessons from the successes and failures of highly relevant initiatives in distant nations. This problem may be attributed to several factors, not the least of which includes the entrenchment of local traditions and ethnocentric assumptions, but surely the quality and relevance of international-comparative research - and the way its results are disseminated - are issues that must also be taken into careful consideration. Careful attention to methodological issues enables us to ensure that research is sufficiently rigorous and convincing and that it directly addresses relevant questions.

Here it is useful to briefly consider what research in this field suggests regarding the case of Latvia. In Latvia, higher education has been transforming in recent years due to both domestic policies and international trends (such as the Bologna Process), which deeply affect teacher education (Dedze \& Catlaks, 2001). Tatjana Koke (2008) observed that Latvia needs "to ensure that higher education becomes an export commodity so that the array of study programmes is innovative and flexible" and that higher education must meet multiple goals, including "for personal development as well as for becoming a fully functioning and competitive member of the society throughout the lifetime." While Latvia is certainly much larger than many countries, the term "small states" has sometimes been used by educational policy researchers to describe Latvia and other nations with a similarly sized population (Crossley, Bray \& Packer, 2011, 9), and for several years international-comparative research has been conducted on the unique challenges shared by the educational systems of such countries (Bray \& Packer, 1993). Much can be learned from careful examination of how educational challenges are successfully (or unsuccessfully) met in small nations in which the effects of policy changes may be relatively immediate and profound. Educational researcher Mark Bray has emphasized the idea that small states may be recognized as having "an ecology of their own rather than being merely scaled-down versions of medium-sized and large states" (Bray, 2011, 62), a point that clearly has implications for the applicability of knowledge derived from larger systems toward the endeavor of educational (or economic) planning in small nations. Bray has suggested that economic vulnerability, isolation and high costs of administration are disproportionately challenging factors in the educational systems of small nations.

It should also be noted that international comparisons based on the category "small state" may sometimes be insufficiently precise, producing simplistic and misleading interpretations, since as Bray has demonstrated, if one considers the world's 89 smallest states and territories, "32 (36 per cent) have populations below 100,000 and thus comprise the smallest of the small. At the other end of the spectrum, only 10 states (11.2 per cent) have populations between 2 and 3 million" (Bray, 2011, 40). In other words, it would seem that Latvia could be most meaningfully considered within a more precise category of "medium-small state", placing it with such peer nations around the world as Slovenia, Lesotho, Macedonia, Namibia, Oman, Mongolia, Jamaica, Kuwait, and Armenia. Yet even use of this category can be misleading, since Latvia is fully integrated with Europe via the European Union and does not face most of the challenges commonly associated with economic isolation. Still, some of the most basic features of education, such as the proportion of public versus private sector enrollment, may 
reveal distinctive characteristics. Latvia, reportedly, is quite different from most of Europe in this regard: "In Europe, most tertiary education systems, including those of small states, are dominated by the public sector. Exceptions among the small states include Estonia and Latvia, where the 2006 share of private sector enrolments was as high as 84 per cent and 96 per cent respectively, and has been progressing since 2004" (Martin, 2011, 85). It follows that it may be advantageous for researchers in Latvia to determine the appropriateness of certain targeted comparisons based on the precise nature of the problem examined, since for particular topics Singapore, Luxembourg, and Abu Dhabi might prove to be far more relevant for comparison than Germany and the USA, for example, and there is little evidence to support the assertion that modeling one's educational or economic system (or research and development policy) on that of the largest nations will necessarily lead to greater success.

\section{Methodological Issues}

International-comparative research must be carefully designed in order to avoid certain common errors and to maximize its relevance and applicability to educational practice. Among the many inherent challenges are the specific problem of how to account for a lack of genuine conceptual equivalency and the more general issue of how to meaningfully represent cultural differences. The risks associated with the first problem are particularly evident when one considers how strategies such as surveys and questionnaires (or "one-off" interviews and brief observations) may mislead researchers seeking psychological or other phenomena that are comprehended differently in different places, such as "self-esteem" or "intrinsic motivation". In many contemporary societies in Asia and Polynesia, for example, such concepts can be viewed very differently than in Europe and North America, so the findings from such an approach will be inevitably superficial if not misleading. This suggests that within relatively underexplored topic areas (or cultural settings) it may be advisable to proceed with long-term, intensive and multifaceted qualitative strategies (such as ethnography) prior to large-scale surveys, yet this raises the problem of sampling and generalizability (or how to interpret the broader significance of sites examined via convenience sampling, and the even larger epistemological problems associated with "action research" interventions, case studies of notable figures, etc.). Eventually, quantitative techniques seem to be necessary in order to generate a more comprehensive and accurate picture of the larger landscape, but design of appropriate instruments may require pioneering work with qualitative strategies to ensure conceptual equivalency and richer, nuanced understandings. In this regard, the interdisciplinary field of education offers a valuable domain in which open-minded scholars may seek to reconcile the diverging aims of economic, anthropological, sociological, and psychological research, since each of these fields, as well as the field of history and others, may legitimately stake an important claim for unique insights into education.

As demonstrated elsewhere (Hebert, 2010), for certain kinds of questions comparison in terms of ethnic or other social divisions may be as meaningful and useful as comparison of entire nation-states. Although this article specifically concerns the topic of internationalcomparative studies, its focus should not be taken to imply that comparison of entire nations is necessarily more appropriate than other kinds of comparisons in research. As Patrick Finney has observed, "the decision to centre analysis on the sovereign state rather than, say, 'humanity as a whole or the individual' is neither necessary nor neutral and actually reifies it, ineluctably reinforcing its political and epistemological claims" (Finney, 2008, 107). Robust internationalcomparisons must not neglect to take into account the diversity of individuals and groups within each nation compared, and the choice to compare at this level (e.g. national systems of 
education) must be clearly rationalized. Readers may wish to consult a special issue on the theme of "Comparative social science: Characteristic problems and changing problem solutions" in the journal Comparative Education for detailed discussion of recent methodological debates in this field (Schriewer, 2006).

\section{Theoretical Paradigms}

While sound methodology is essential toward ensuring that a study produces convincing findings, careful attention to theoretical issues ensures that research findings contribute to the collective construction of meaningful explanations and a broader understanding of humanity. However, each theory inevitably has distinctive "blind spots" that must be acknowledged, and ultimately, few theories have withstood the test of time. There are many advantages to producing studies that are grounded in (and responsive to) current theory, contributing to the generation of holistic explanations, while also simultaneously balanced with sufficiently rich empirical data so as to remain a significant contribution to knowledge even if the theoretical component is later determined to be unfashionable (or even irrelevant) far in the future. For now, there are some particular theoretical paradigms that tend to be of great interest to scholars in the field of international-comparative education, and therefore call for some discussion in this article.

\section{Globalization}

According to Stuart Hall and other notable theorists, globalization is a distinctive phenomenon of the contemporary world with processes operating on a global scale that cut across community, regional, and national borders, integrating and connecting communities in new spacetime configurations via the evermore rapid and convenient exchange of people, products, and ideas. Globalization may also be defined as a shift in spatial-temporal processes that "rapidly cut across national boundaries, drawing more of the world into webs of interconnection, integrating and stretching cultures and communities across time and space, and compressing our spatial and temporal horizons" (Inda \& Rosaldo, 2002, 9), and its distinctive features include global flows of communication and trade that increasingly transcend national boundaries, leading to a widespread state of global interdependence. A related concept that may be seen as a kind of response to some tendencies associated with the general trend of globalization is "glocalization", by which local concepts and practices receive unprecedented emphasis. In the field of education, it seems reasonable to suggest that the global popularization of specific kinds of computer software widely used in schools, or such phenomena as the Bologna Process and PISA testing may be considered in relation to globalization, yet the development of new curriculum concerning local ethnic groups may be seen as a form of glocalization while also part of a related phenomenon known as multiculturalism.

\section{Multiculturalism}

As James Banks explains in Routledge International Companion to Multicultural Education, multicultural education is "a concept, an educational reform movement, and a process" that "incorporates the idea that all students - regardless of their ethnic, racial, cultural, or linguistic characteristics - should have an equal opportunity to learn in school" (Banks, 2009, 1). The notion of multiculturalism continues to be debated worldwide, including in contemporary Europe. When considered from an historical perspective, it becomes clear that this way of thinking about education has only become popular in recent generations, for "in most nations both the contents and methods of education have tended to alienate students whose identities differ from the dominant culture" (Hebert \& Karlsen, 2010, 6). Examples of research concerning multicultural issues in Latvian schools include studies of language policy in relation to curricular 
change (Hogan-Brun, 2006) and research on the status of schools for ethnic minorities (Golubeva \& Austers, 2011). Multiculturalism is not without its critics, yet much criticism of this movement may be due to misunderstandings. Carl Grant (2008), editor of the multi-volume History of Multicultural Education observed that "Both radical and conservative critics of multicultural education often leave their research skills, scholarship, and willingness to conduct a thorough review of educational literature at the academy door" when writing of teachers' efforts to develop more relevant and effective curriculum and instruction for students from culturally diverse backgrounds (Grant, 2008, 318). As nations on every continent become increasingly diverse via immigration and international exchange, multiculturalism has arisen as an important topic in educational research and practice.

\section{Postcolonialism and Indigenous Epistemologies}

Another important theme often encountered in international-comparative education research is that of postcolonialism, as well as new forms of research this condition has engendered, often known as "decolonizing methodologies" (Lincoln \& Gonzalez, 2008). To reach an understanding of these concepts, it may be helpful to briefly consider a proverb common among the Māori of Aotearoa (New Zealand): "Whāia te mātauranga hei oranga mō koutou" ("Seek after learning for the sake of your wellbeing"). As this proverb illustrates, contrary to common stereotypes, a love of learning is celebrated in many indigenous cultural traditions, yet as multiculturalism teaches us, it may be love for a kind of learning that is different from that commonly associated with books and institutionalized in schools based on European traditions. One of the challenges associated with nations that seek to recover their cultural heritage following colonization is how to resolve inherent tensions between locally valued understandings (or indigenous epistemologies), and that which is valued worldwide, which tends to be largely based on European models. Indigenous methodologies are approaches to research that seek via close collaboration with indigenous people to recover and affirm local cultural heritage. This approach to research may have profound implications for education in nations that have been colonized by foreign powers, and a relevant question sometimes raised by scholars is the extent to which postcolonial theory may even apply to some aspects of the conditions in states formerly associated with the USSR (Carey \& Raciborski, 2004), despite the fact that many of these states are clearly European at heart. Readers may wish to consult special issues of the journal Comparative Education on the themes of "Postcolonialism and Comparative Education" (Crossley \& Tikly, 2004) and "Indigenous education: Addressing current issues and developments" (May \& Aikman, 2003) for detailed discussion of these related topics.

\section{Democracy and Social Justice}

Most of the above theoretical orientations and research paradigms are to some extent also encompassed within the broader themes of democracy and social justice, at least when applied to the field of education, for inherent to each is an underlying interest in promoting equity and egalitarian approaches in terms of both curriculum and policy. Nevertheless, it is important to consider that while the notion of equality sought by such movements is regarded as a treasured ideal, it is only realistic to acknowledge equality and democracy as attractive yet impossible ideals to ever fully attain (Blackburn, 2008). Moreover, many forms of democracy in actual practice easily become a kind of "tyranny of the majority". Within the context of such theories, the themes of democracy and equality may serve as a kind of antithesis within a sort of Hegelian dialectic against which evidence of oppressive social forces is juxtaposed. Critical examination of such juxtapositions may encourage the development of creative solutions that 
serve to minimize the widespread forms of oppression that seem to be largely part of the human condition worldwide. Among the more interesting and compelling new applications of these principles to the field of lifelong education (and educational technology in particular) is the opensource and "wikification" movements, that seek to develop protocols for freedom of information, with the vision of offering unfettered access to massive amounts of free data from which anyone at any time may learn via the Internet (Khan Academy, n. d.; Suoranta \& Vaden, 2010). Related developments such as You tube now enable countless numbers of people worldwide to instantly access amateur lessons, empowering them to learn how to do most anything, from assembling furniture to playing guitar. These developments also have important implications for education in schools, and may require educators to reassess, frame and prioritize their work in different ways, so schools continue to be on the frontier of knowledge dissemination.

The themes mentioned above are by no means unique to the interdisciplinary field of comparative education, and may in fact be recognizable across much current work in the humanities and social sciences (Burke, 2005). Much of my own research across recent years has emphasized similar themes in relation to the specific subject area of music education, including such matters as the construction of national and ethnic identity via music teaching (Hebert, 2010, 2012; Hebert \& KertzWelzel, 2012), and the obligations of music educators to appropriately respond to multiculturalism (Hebert \& Karlsen, 2010; Heimonen \& Hebert, 2010). Although to scholars in other fields music might seem to be an aesthetic subject matter for which such concerns are tangential, these themes have actually had a profound influence lately on music teaching across much of the world. Teacher educators in other subject areas - from literature to athletics - may similarly find internationalcomparative research studies that address such themes in interesting ways.

A final matter that requires some discussion here is the extent to which research may actually inform practice. This seems to be a perennial challenge in the field of education, for researchers and practitioners often struggle to communicate to each other, leading to what is perceived as irrelevant "ivory tower" theorization as well as the equally challenging problem of great ideas merely remaining in libraries rather than actually put into practice by teachers. Clearly, more attention must be paid to how theories are put into practice. Fortunately, new technologies may also be of some help in this regard, since it is now more convenient than ever before for researchers to connect directly with what is happening in classrooms through such means as videoconferencing and social media, and these kinds of technologies also enable presentation of the applications of research findings to be offered in a format that is more digestible to the average teacher than research reports, for example using online and virtual (interactive) formats via multimedia presentations, and other forms beyond the standard written text. Careful attention to both theoretical and methodological issues will ensure that international-comparative studies are designed to contribute to the answering of relevant questions using techniques that are rigorous and convincing, and that contribute to the construction of broader theoretical explanations.

\section{Perennial Challenges and New Opportunities}

Like many other scholarly fields, educational research proceeds from development of a holistic and rather superficial overview toward attainment of more precise and reliable knowledge based on careful examination of specific questions. In a field such as biology, for comparison, it is widely understood that scientists begin with merely identifying the vast array of animal species in the world, describing their physical attributes and native habitat, only later reaching an understanding of the life cycle and daily behavior of the very most unusual creatures, and eventually even documenting their anatomical structures at the cellular level. International- 
comparative studies in education similarly may begin with simplistic descriptions in such fields as mathematics, for which identical testing can be conveniently implemented in schools throughout the world, as seen in the PISA test. Still, as discussed in my introduction, while numeracy is certainly of great value to many professions, it is surely only one component of a robust education, and international comparative research must advance to encompass a broader swath of learning far beyond mathematics. Many important forms of understanding and ability that are greatly valued by humanity - empathy and originality, for example - call for the development of stronger research-based knowledge in educational contexts. How can international-comparative education meaningfully examine subjects beyond the reach of standardized testing, in such domains as the fostering of: creativity, talent, and ethical sensibilities? This is an important area to which greater attention is needed in international comparative education research, and many future opportunities are evident in this domain of inquiry. The urgency of research in such areas seems especially evident in light of the increasing imbalance commonly seen due to evaluation mandates, some of which, regrettably, are bolstered by policy decisions that place inappropriate emphasis on comparative testing regimes, such as the PISA test (see Picture 1).

\section{Picture 1. Effects of Evaluation Mandate on Balance of Contemporary Educational Systems}

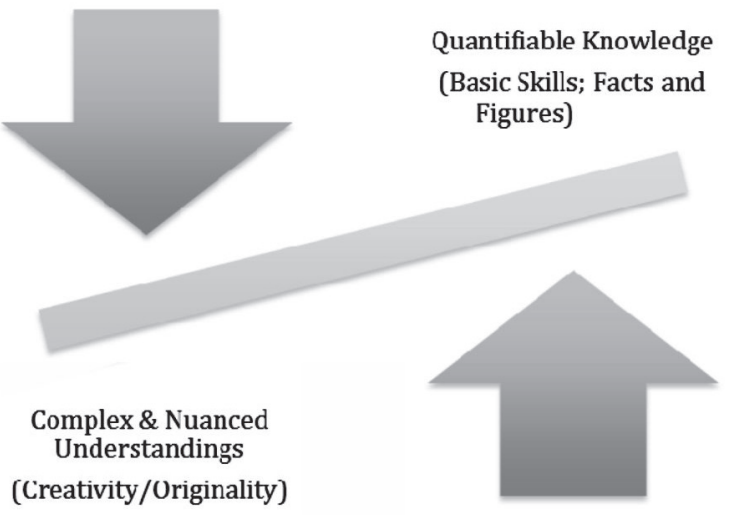

Due to evaluation mandates, "Literacy and Numeracy" concerns often threaten all other educational objectives (e.g., creativity, ethics, knowledge of history, etc.) in various educational systems due to unbalanced policy-making. Facing a perceived need to be more "internationally competitive" teachers often sense pressure to "teach to the test", which ultimately results in superficial education. Author would suggest that one solution to this dilemma is to embark on more extensive international-comparative studies of the kinds of topics that lie outside the reach of such testing regimes. If research enables far greater attention to be paid to such qualities as originality, creativity, historical/global awareness and ethics, the educational policy landscape may be transformed. Studies that are clearly rooted in contemporary educational philosophy will find a robust foundation for research on such topics, for these are clearly related to the aforementioned theme of leaving a better world to the next generation. Researchers in this field may find it is worthwhile to become familiar with relevant organizations, such as the Organization for Economic Cooperation and Development (OECD), the Comparative and International Education Society (CIES), and the World Council of Comparative Education Societies (WCCES). It is also important to examine prospective funding sources for this form of research, such as the European Union and UNESCO, both Nordplus and Nordforsk in Northern Europe, as well as the national research councils associated with many individual nations in Europe and beyond.

\section{RESULTS}

\section{Practical Suggestions and Policy Recommendations}

This article has offered an overview of issues and concepts in the field of internationalcomparative education as well as some discussion of the unique promises associated with this 
form of research. However, the need for international awareness may be a much broader concern than something resolved through research alone. In Table 1. Practical Suggestions for Globally Conscious Teaching (see Table 1), author offers some ideas that teacher educators might share with their students who intend to become school teachers.

\section{Table 1. Practical Suggestions for Globally Conscious Teaching}

\section{Practical Suggestions for Globally Conscious Teaching}

1. International Colleaguality: You may have as much in common with a teacher from Australia as you do with a truck driver or attorney from your hometown. It cannot hurt to nurture personal friendships with teachers from distant nations and cultures and frequently share ideas with them. Online social networking can be helpful.

2. Universal vs. Local Challenges: Effective teaching is not easy. While some issues and challenges faced by teachers are unavoidable, we may have a lot to learn from what has worked for teachers in other places when they were confronted with various difficulties.

3. Educational Resources: Outstanding materials are available to strengthen and update all aspects of your teaching. Although much can be found online nowadays, it is also important to regularly examine research journals in a good library to keep abreast of the latest specialized knowledge in one's field.

4. Responding to New Technologies of Globalization. Even for technophobes it is important to keep up with the technologies used by students. Tools like Skype and You tube can enable you to establish and maintain contact with innovative teachers around the world and even to connect your students with global peers.

Contemporary philosopher Martha Nussbaum has demonstrated how timeless studies in the humanities retain their universal importance even in times of great economic strain (Nussbaum, 2010), and the same can certainly be said of the fine arts, which uniquely nurture one's ability to produce objects of expression and beauty that transcend the ordinary, mechanical, and mundane, giving meaning to life. Based on examination and synthesis of recent studies in the field of international comparative education, author would like to also propose some ideas for consideration by those associated with educational policy development in small nations (see Table 2).

\section{Table 2. Educational Policy Recommendations for Small Nations}

\section{Educational Policy Recommendations for Small Nations}

1. Theoretical Knowledge vs. Practical Skills. Economic crises tend to highlight the perennial tension inherent within any curriculum between development of theoretical knowledge and practical skills. Although industry can be counted on to consistently claim that practical skills are more urgently needed than ever before, only theoretical knowledge can contribute to transforming the problems of industry. Thus, a balance is needed between these emphases during both periods of prosperity and periods of decline.

2. Language Policy. English language is unrivaled nowadays as the major form of global communication in research, diplomacy and industry, yet there is a need to supplement emphasis on English proficiency with other areas of emerging importance (e.g., Chinese) and to balance these with an appropriate commitment to nurturing and sustaining local languages, such as Latvian or Norwegian.

3. Economic Concerns. Aiming for advanced development of highly specialized industries is advisable for smaller nations in the current economic climate, which means that education should emphasize the fostering of originality and creativity, international awareness, and skills in communication and cooperation. It follows that the arts and humanities fields continue to be of great importance in higher education, for they uniquely enable comprehensive development of these valued competencies. 


\section{CONCLUSIONS}

This article has offered discussion of the field of international-comparative education, based on the following themes: (1) What are the unique lessons to be learned from international comparisons, and what are the prospective risks for how such comparisons may be misinterpreted and misused in educational settings?; and (2) How can international comparative research be made more relevant, with tangible applications that may be recognized and effectively used by school teachers? These questions were examined from various angles, including consideration of how research can proceed with greater effectiveness. In conclusion, author would like to suggest that comparative research is uniquely insightful and necessary, that it must increasingly move beyond mere comparison of math scores (e.g., PISA), and that more studies are needed in the less quantifiable topics: creativity, talent, ethical sensibilities, etc. Comparative research should be more carefully based on recent concerns in the philosophy of education and current social science methodologies, and effective use of new technologies may enhance dissemination and application of research results. Finally, author would also suggest that a comparative lens be considered in the write-up of any study. A thorough literature review and discussion in relation to similar work in other locations enables broader application of findings. Author hopes that readers will have found some stimulating ideas in this article that prompt them to more carefully examine the promising field of international-comparative education.

\section{REFERENCES}

Banks, J. A. (Ed.). (2009). Routledge international companion to multicultural education. London: Routledge.

Blackburn, R. M. (2008). What is social inequality? International Journal of Sociology and Social Policy, 28 (7/8), 250-259.

Bray, M. (2011). The small states paradigm and its evolution. In M. Martin, \& M. Bray (Eds.), Tertiary education in small states: Planning in the context of globalization (pp. 37-72). Paris: UNESCO Publishing.

Bray, M., \& Packer, S. (1993). Education in small nations: Concepts, challenges, and strategies. Oxford: Pergamon Press.

Burke, P. (2005). History and social theory ( $2^{\text {nd }}$ ed.). Ithaca: Cornell University Press.

Carey, H. F., \& Raciborski, R. (2004). Postcolonialism: A valid paradigm for the former Sovietized states and Yugoslavia? East European Politics and Societies, 18 (2), 191-235.

Crossley, M., Bray, M., \& Packer, S. (2011). Education in small states: Policies and priorities. London: Commonwealth Secretariat.

Crossley, M., \& Tikly, L. (2004). Postcolonial perspectives and comparative and international research in education: A critical introduction. Comparative Education, 40 (2). Special Issue 28: Postcolonialism and Comparative Education, 146-156.

Finney, P. (2008). Hayden White, international history and questions too seldom posed. Rethinking History, 12 (1), 103-123.

Golubeva, M., \& Austers, I. (2011). Alternative civil enculturation: Political disenchantment and civic attitudes in minority schools in Estonia, Latvia, and Slovakia. European Education, 42 (4), 49-68.

Grant, C. (2008). Challenging the myths about multicultural education. In C. A. Grant \& T. K. Chapman (Eds.), History of Multicultural Education, volume II: Foundations and Stratifications (pp. 316-325). London: Routledge. 
Hebert, D. G. (2012). Wind bands and cultural identity in Japanese schools. Dordrecht and New York: Springer.

Hebert, D. G. (2010). Ethnicity and music education: Sociological dimensions. In R. Wright (Ed.), Sociology and Music Education (pp. 93-114). Aldershot: Ashgate Press.

Hebert, D. G., \& Karlsen, S. (2010). Editorial introduction: Multiculturalism and music education. Finnish Journal of Music Education, 13 (1), 6-11.

Hebert, D. G., \& Kertz-Welzel, A. (Eds.). (2012). Patriotism and nationalism in music education. Aldershot: Ashgate Press.

Heimonen, M., \& Hebert, D. G. (2010). Pluralism and minority rights in music education: Implications of the legal and social philosophical dimensions. Visions of Research in Music Education, 15. Retrieved January 15, 2013, from http://users.rider.edu/ vrme/

Hogan-Brun, G. (2006). At the interface of language ideology and practice: The public discourse surrounding the 2004 education reform in Latvia. Language Policy, 5, 313-333.

Inda, J. X. \& Rosaldo, R. (Eds.). (2002). The anthropology of globalization: A reader. London: WileyBlackwell.

Khan Academy. (n. d.). Khan Academy: Learn almost everything for free. Retrieved January 15, 2013, from http://www.khanacademy.org

Koke, T. (2008). Higher education for the development of Latvia. Signum Temporis: Journal of Research in Pedagogy and Psychology, 1 (1), 4-9.

Lincoln, Y. S., \& Gonzalez, E. M. (2008). The search for emerging decolonizing methodologies in qualitative research: Further strategies for liberator and democratic inquiry. Qualitative Inquiry, 14 (5), 784-805.

Martin, M. (2011). Meeting social demand for quantity and quality. In M. Martin, \& M. Bray, (Eds.), Tertiary education in small states: Planning in the context of globalization (pp. 73-100). Paris: UNESCO Publishing.

May, S. \& Aikman, S. (2003). Indigenous education: Addressing current issues and developments. Comparative Education, 39 (2). Special Issue 27: Indigenous Education: New Possibilities, Ongoing Constraints, $139-145$.

Nussbaum, M. C. (2010). Not for profit: Why democracy needs the humanities. Princeton, NJ: Princeton University Press.

Schriewer, J. (2006). Comparative social science: Characteristic problems and changing problem solutions. Comparative Education, 42 (3). Special Issue 3: Comparative Methodologies in the Social Sciences: Cross-Disciplinary Inspirations, 299-336.

Suoranta J. \& Vaden, T. (2010). Wikiworld. New York: Pluto Press.

\section{Professor David G. Hebert}

Faculty of Education

Bergen University College

Address: Post 7030, Bergen 5020, Norway

Phone: +47 55587500

E-mail: davidgabrielmusic@yahoo.com 